\title{
Preparation and electromagnetic properties of zinc ferrite/expanded graphite composites
}

\author{
GuOZhu Shen $^{1 *}$, Songtao Yu ${ }^{2}$, YuAn CAO $^{1}$ \\ ${ }^{1}$ School of Physics and Optoelectronic Engineering, Nanjing University of Information Science \& Technology, \\ Nanjing 210044, China \\ ${ }^{2}$ Shanghai Research Institute of Chemical Industry, Shanghai 200062, China
}

\begin{abstract}
An effective process for the synthesis of nano spinel zinc ferrite/expanded graphite composites was developed in order to get an electromagnetic interference shielding material. Firstly, expandable graphite was prepared using sulfuric and nitric acid solutions. Then, the precursor of the composites was produced by chemical co-precipitation method, followed by heating treatment. The obtained composites were characterized by X-ray diffraction and scanning electron microscopy. The dielectric and magnetic properties were determined using vector network analyzer and vibrating sample magnetometry. The results showed that ferrite nanoparticles with the sizes of about $50-150 \mathrm{~nm}$ were uniformly dispersed on the surface and interspace of EG. The magnetic properties of the composites changed by adjusting the ferrite/EG ratio and the composites had high dielectric constant in the range of $2-18 \mathrm{GHz}$. These properties of the prepared composites suggest that they can be used as a promising electromagnetic interference shielding material.
\end{abstract}

Keywords: ferrite; graphite; composites; nanocomposites; magnetic properties

(C) Wroclaw University of Technology.

\section{Introduction}

Recently, electromagnetic interference (EMI) shielding materials have been extensively studied for their potential application both in civil and military fields [1-5]. Typically, metals have been used as EMI shielding materials as they have high conductivity and dielectric permittivity. However, metal materials used as shielding materials have many disadvantages such as high density, poor processing performance, and susceptibility to corrosion [6-8]. Graphite is an excellent and low cost electrical conductor characterized by uniformity and good resistance to corrosion, oxidation and wear, therefore it is the most promising EMI shielding material in place of metals $[9,10]$. However, the shielding effectiveness of graphite is unsatisfactory at certain frequencies due to its non-magnetic nature. Many treatments have been used to exploit the application of graphite materials, including coating, plating of surface with a layer of metal or com-

*E-mail: shengz@nuist.edu.cn pound, preparation of intercalated compounds and expanded graphite (EG) in a shape of nanoflakes, etc. [11-18]. Spinel-type ferrites are important soft magnetic materials with excellent chemical stability, good mechanical hardness, precise control on the composition and easy preparation by chemical processing using solutions [19-24]. In order to improve the shielding effectiveness of EG materials, EG composites can be formed by loading nanomagnetic spinel ferrites onto the surface of EG. By means of this method, the composites may be endowed with magnetic features without significantly decreasing the intrinsic electric conductivity of EG.

In the present work, we report on deposition of single-phase nano spinel zinc ferrite $\left(\mathrm{ZnFe}_{2} \mathrm{O}_{4}\right)$ particles onto EG by chemical co-precipitation method. One of our aims is to develop a method of expandable graphite production and adjust magnetic and dielectric properties of graphite composites in order to enhance the EMI shielding effectiveness. Firstly, expandable graphite was prepared using sulfuric acid and nitric acid solutions. Then, the single-phase nano spinel zinc ferrite 
$\left(\mathrm{ZnFe}_{2} \mathrm{O}_{4}\right)$ particles were deposited onto the expandable graphite by chemical co-deposition and heating treatment method.

\section{Experimental}

The starting materials used were natural flakes of graphite with an average diameter of $500 \mu \mathrm{m}$. In chemical procedures $\mathrm{HNO}_{3}(65 \%), \mathrm{H}_{2} \mathrm{SO}_{4}(98 \%)$, $\mathrm{Zn}\left(\mathrm{NO}_{3}\right)_{2} \cdot 6 \mathrm{H}_{2} \mathrm{O}, \mathrm{Fe}\left(\mathrm{NO}_{3}\right)_{3} \cdot 9 \mathrm{H}_{2} \mathrm{O}$ and $\mathrm{NaOH}$ were used. In order to prepare expandable graphite, firstly, the natural graphite was treated with $\mathrm{HNO}_{3}$ and $\mathrm{H}_{2} \mathrm{SO}_{4}$ (at the ratio $1: 2, \mathrm{~V} / \mathrm{V}$ ) with vigorous stirring for $30 \mathrm{~min}$, then the treated graphite was filtered and washed with distilled water until the $\mathrm{pH}$ level of the solution reached 6.2, and dried at $70{ }^{\circ} \mathrm{C}$. The resulting graphite intercalation compound was heated at $600{ }^{\circ} \mathrm{C}$ for $1 \mathrm{~min}$ in a muffle furnace to form EG, then denoted as sample $\mathrm{S} 1$. In order to obtain zinc ferrite/EG composites, $\mathrm{Zn}\left(\mathrm{NO}_{3}\right)_{2} \cdot 6 \mathrm{H}_{2} \mathrm{O}(1.49 \mathrm{~g})$ and $\mathrm{Fe}\left(\mathrm{NO}_{3}\right)_{3} \cdot 9 \mathrm{H}_{2} \mathrm{O}$ $(4.04 \mathrm{~g})$ were dissolved in $50 \mathrm{ml}$ of water, and the formerly prepared expandable graphite $(1.00 \mathrm{~g})$ was dispersed in the solution. After treating the solution under ultrasonic irradiation for $15 \mathrm{~min}, 25 \mathrm{ml}$ solution of $\mathrm{NaOH}(1.75 \mathrm{~g})$ was added to the above solution. The mixture was stirred for $12 \mathrm{~h}$ for ion exchange, and then filtered and dried at $70{ }^{\circ} \mathrm{C}$ for $24 \mathrm{~h}$. The obtained specimen was put into a muffle furnace at room temperature under air atmosphere, then the furnace temperature was raised to $600{ }^{\circ} \mathrm{C}$ at a rate of $5{ }^{\circ} \mathrm{C} / \mathrm{min}$, and the specimen was kept for $1 \mathrm{~min}$ at the temperature. The obtained sample was named S2. Similarly, the sample S3 was produced by adding $25 \mathrm{ml}$ of solution of $\mathrm{NaOH}(2.50 \mathrm{~g})$ to $50 \mathrm{ml}$ of solution containing $\mathrm{Zn}\left(\mathrm{NO}_{3}\right)_{2} \cdot 6 \mathrm{H}_{2} \mathrm{O}$ $(2.23 \mathrm{~g}), \mathrm{Fe}\left(\mathrm{NO}_{3}\right)_{3} \cdot 9 \mathrm{H}_{2} \mathrm{O}(6.06 \mathrm{~g})$ and the expandable graphite $(1.00 \mathrm{~g})$, and further process was the same as in the case of sample S2. In order to be able to measure electromagnetic parameters (complex permittivity and permeability), the samples $\mathrm{S} 2$ and S3 were homogenously mixed with paraffin wax ( $70 \%$ by weight) and toroidal-shaped samples with outer and inner diameters of $7 \mathrm{~mm}$ and $3 \mathrm{~mm}$, respectively were prepared from the composites.

The phase composition of the samples was identified by X-ray diffraction (XRD) (DX-2000)

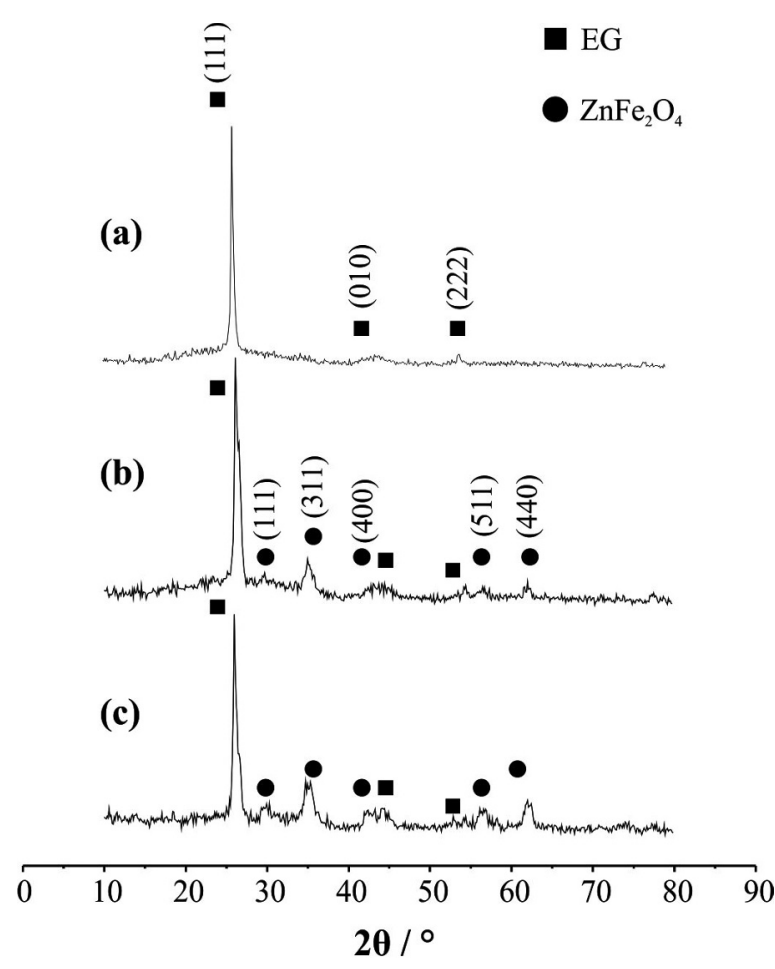

Fig. 1. XRD patterns for the samples: (a) S1; (b) S2; (c) S3.

operating at $35 \mathrm{kV}$ and using $\mathrm{Cu} \mathrm{K} \alpha$ radiation. The morphology of the samples surfaces was observed by scanning electron microscopy (SEM) (FEI Sirion). The magnetic hysteresis loops of the samples were measured with a vibrating sample magnetometer (VSM) (Lakeshore 7300) operating at room temperature. The electromagnetic parameters of the samples were determined by a vector network analyzer (Agilent E8363C) at the frequency range of $2-18 \mathrm{GHz}$.

\section{Results and discussion}

\subsection{Characterization of samples}

XRD patterns for the samples S1, S2 and S3 are shown in Fig. 1. Fig. 1(a) shows the XRD pattern of the sample $\mathrm{S} 1$ with three peaks at $2 \theta=26.32^{\circ}, 43.40^{\circ}$ and $54.50^{\circ}$ (standard data of JCPDS 75-2078). Fig. 1(b) and 1(c) show the XRD patterns of zinc ferrite/EG composites for samples $\mathrm{S} 2$ and $\mathrm{S} 3$ with different loading of $\mathrm{ZnFe}_{2} \mathrm{O}_{4}$. EG 
was found to be the main phase in the two samples. The main peaks of cubic spinel $\mathrm{ZnFe}_{2} \mathrm{O}_{4}$ were also found in both XRD pattern for S2 and S3 samples (standard data of JCPDS 89-1012).

Fig. 2(a) and 2(b) show the SEM images of the zinc ferrite/EG composites for samples $\mathrm{S} 2$ and S3 with different loading of $\mathrm{ZnFe}_{2} \mathrm{O}_{4}$. As shown in Fig. 2(a), the EG is microflaked and composed of multilayer graphite structures with open spaces. The big enough interspace between the two layers may be occupied by the ferrite nanoparticles. In fact, Fig. 2(a) shows the ferrite particles with the sizes of about $50-150 \mathrm{~nm}$ that are uniformly dispersed on the surface and interspace of EG. Fig. 2(b) shows similar image to Fig. 2(a) with the difference that more nanoparticles are dispersed on the surface and interspace of EG because of higher loading of ferrites for the sample S3.

\subsection{Magnetic measurements}

Magnetic measurements of EG and zinc ferrite/EG composites were performed using the VSM technique. The magnetic hysteresis loops at room temperature versus applied magnetic field up to $10 \mathrm{kOe}$ are shown in Fig. 3 and Fig. 4. Due to the energy band structure features, graphitic materials have the diamagnetic susceptibility [25, 26]. As shown in Fig. 3, the result of measurement of the sample $\mathrm{S} 1$ confirms the diamagnetism of EG. Fig. 4 shows that the change in material composition due to different coating of ferrite material resulted in modification of magnetic properties from diamagnetic to ferromagnetic. Obviously, the samples S2 and S3 show better soft magnetic performance. The saturation magnetization (Ms) for the sample S2 and S3 is about $2.4 \mathrm{emu} / \mathrm{g}$ and $3.4 \mathrm{emu} / \mathrm{g}$, respectively. The higher Ms value of the sample S3 than those of the sample S2 is due to increased ferrites content in the sample S3. However, the coercivities $(\mathrm{Hc})$ for the sample S2 (about $110 \mathrm{Oe}$ ) and S3 (about $122 \mathrm{Oe}$ ) are comparable. The comparable Hc resulted from small size effect or nanoregime of materials. According to the nanoregime, magnetic nanomaterials reveal a changeover from multi-domain nature to singledomain nature, and the coercivity of nanomaterials is mainly attributed to the demagnetization caused by single-domain rotation [27]. Thus, the comparable nano size of ferrite particles for the sample S2 and $\mathrm{S} 3$ resulted in the comparable coercivity of the two composites [28].

\subsection{Dielectric and magnetic properties}

The variation of complex permittivity and permeability of ferrite/EG composites with frequency is shown in Fig. 5 and 6. Fig. 5 represents the variation of real part $\varepsilon^{\prime}$ and imaginary part $\varepsilon^{\prime \prime}$ of the complex permittivity for the samples S2 and S3, respectively. It was found that the values of $\varepsilon^{\prime}$ and $\varepsilon^{\prime \prime}$ of the sample S2 are larger than those of sample S3 in the measured range of frequency, and $\varepsilon^{\prime}$ and $\varepsilon^{\prime \prime}$ of the two samples significantly decrease with increasing frequency (see Fig. 5). This can be explained as follows: the weight proportion of EG in the sample $\mathrm{S} 2$ is higher than those in the sample S3, and the value of complex permittivity is determined by the EG material. Fig. 6 shows that the values of real part $\mu^{\prime}$ and imaginary part $\mu^{\prime \prime}$ of complex permeability of the sample S3 are higher than those of the sample S2. Since the values of complex permeability are determined by the magnetic material, this can be attributed to higher weight proportion of ferrites in the sample S3. Furthermore, it is seen that the values of $\mu^{\prime}$ of the two samples are lower than 1 in the measured range of frequency (see Fig. 6). The possible reason is that $\mathrm{EG}$, which is diamagnetic substance, can adjust the values of $\mu^{\prime}$. According to the above analysis, the ferrites/EG composites are good electromagnetic shielding materials, and the electromagnetic shielding properties can be changed by adjusting the ferrite/EG ratio.

\section{Conclusion}

In this paper, the nano zinc ferrite/EG composites were obtained by chemical co-precipitation and heating treatment method. The ferrite particles with sizes of about $50-150 \mathrm{~nm}$ were uniformly dispersed on the surface and interspace of EG. Adding of ferrites into the composites resulted in modification of magnetic properties of EG from diamagnetic to ferromagnetic, and the saturation 

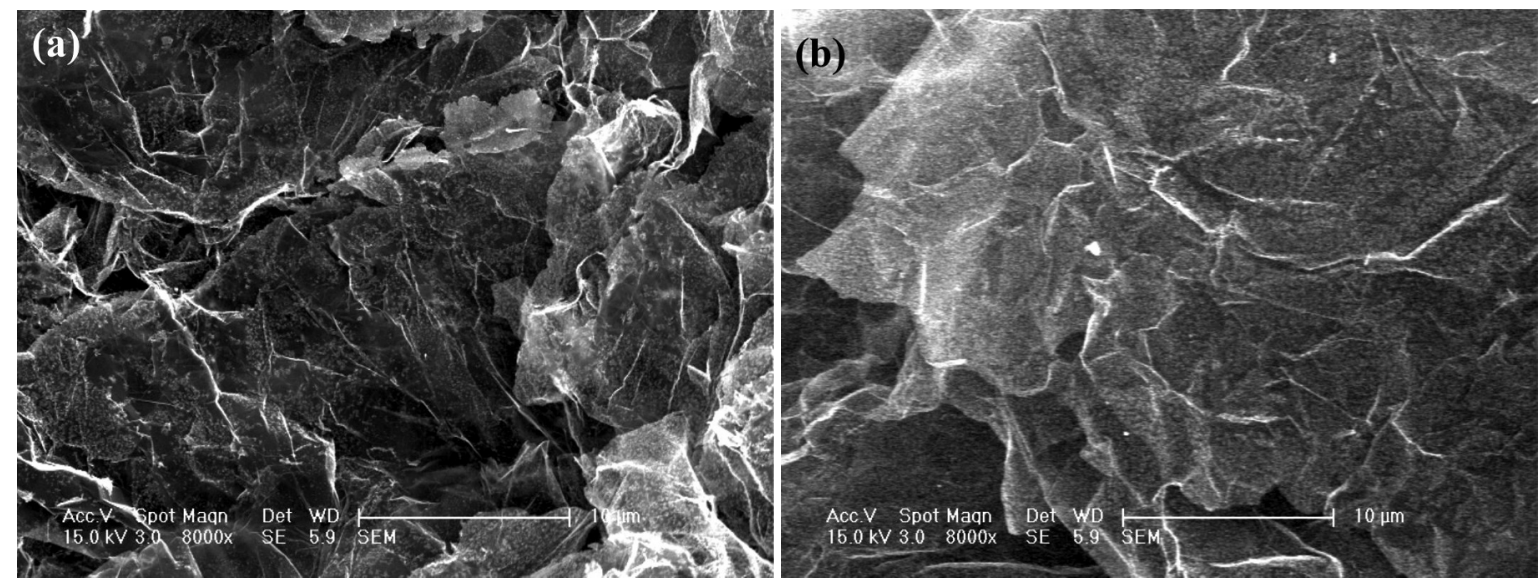

Fig. 2. Typical SEM images for composites samples: (a) S2; (b) S3.

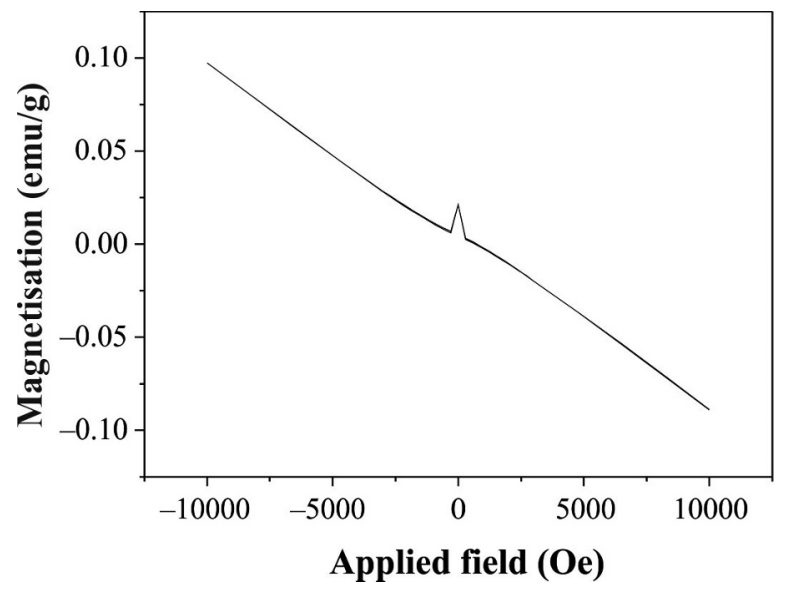

Fig. 3. Hysteresis loop at room temperature for sample S1.

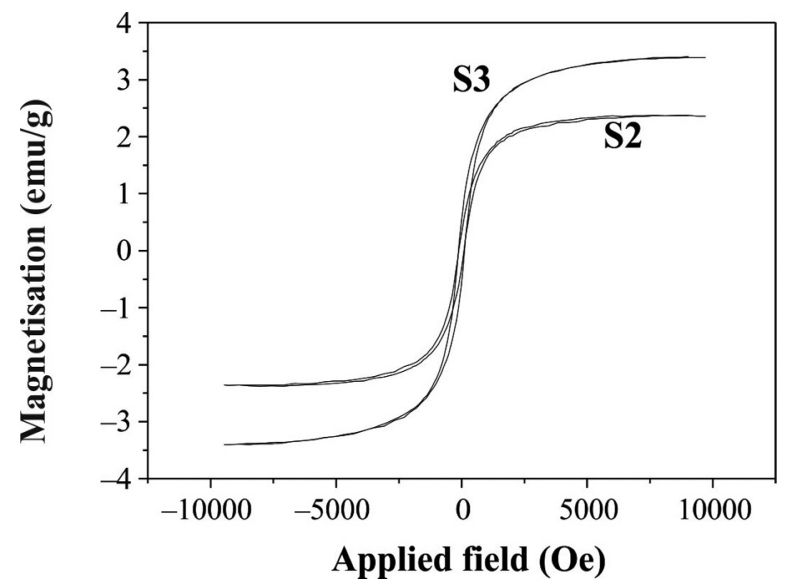

Fig. 4. Hysteresis loops at room temperature for samples S2 and S3.
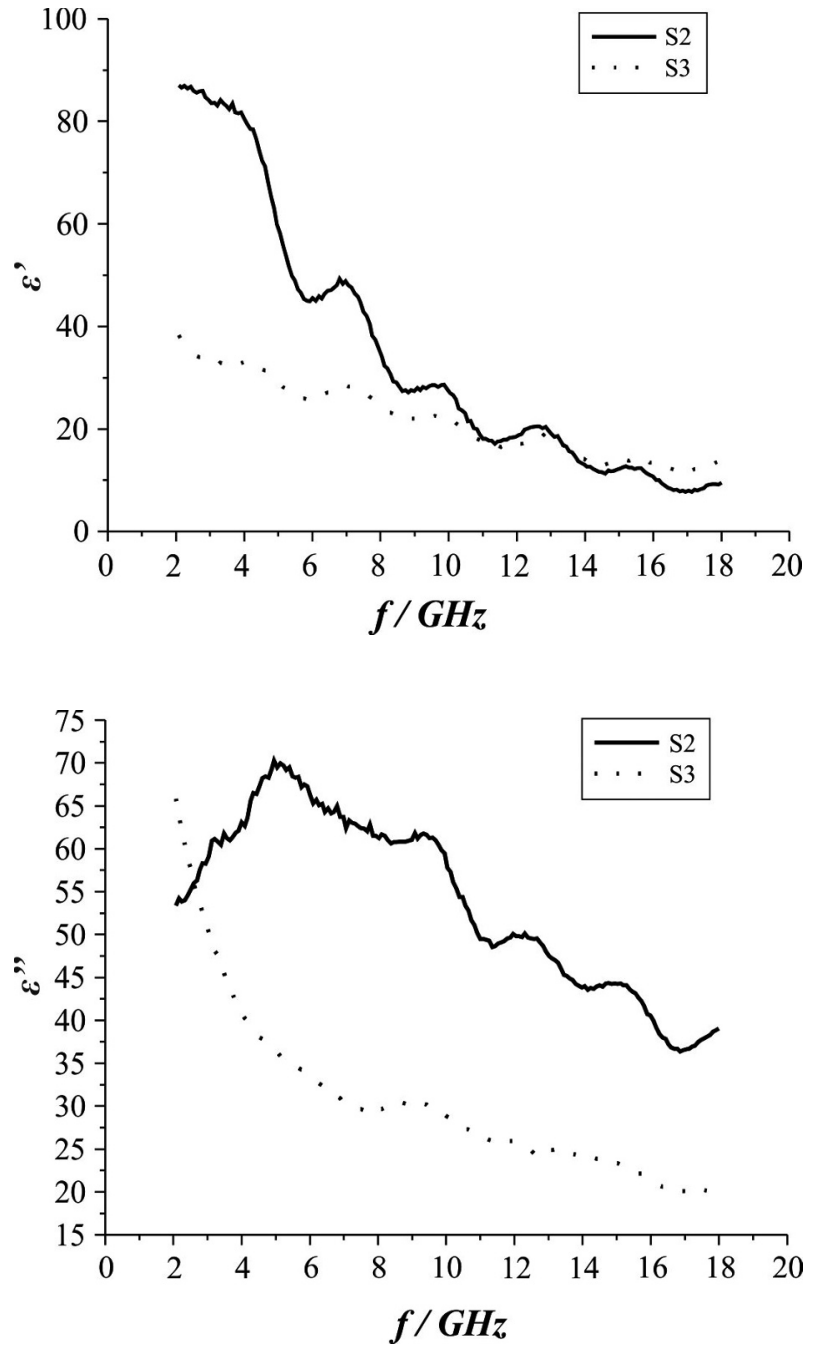

Fig. 5. Variation of complex permittivity of samples S2 and $\mathrm{S} 3$ with frequency. 

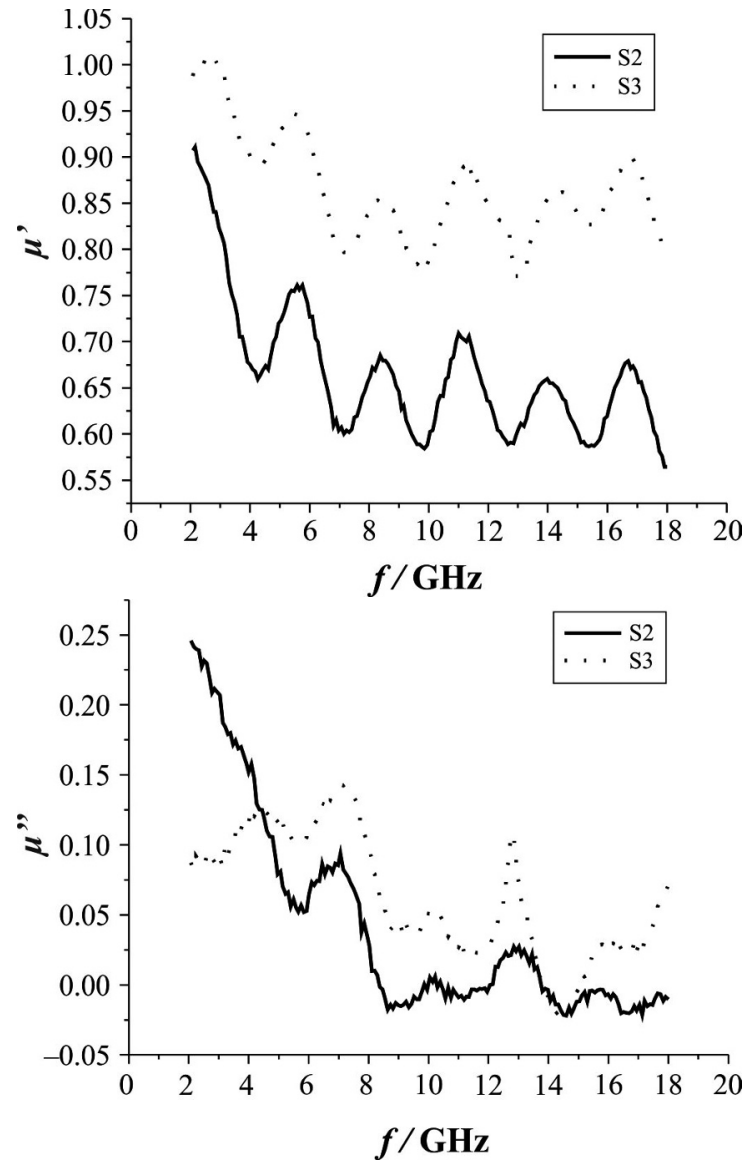

Fig. 6. Variation of complex permeability of samples S2 and S3 with frequency.

magnetization of the composites was increased with the increase of ferrites content. Due to the existing of electrically conductive EG, the composites had high dielectric constant in the range of $2-$ $18 \mathrm{GHz}$.

\section{Acknowledgements}

This work has been supported by Jiangsu Overseas Research \& Training Program for University prominent young $\&$ middle-aged teachers and presidents.

\section{References}

[1] Al-Saleh M.H., SaAdeh W.H., Sundararaj U., Carbon, 60 (2013), 146.

[2] Bantsis G., Betsiou M., Bourliva A., Yioultsis T., SiKalidis C., Ceram. Int., 38 (2012), 721.

[3] Kaur A., Ishral, Dhawan S.K., Synthetic Met., 162 (2012), 1471.

[4] Jang C.K., PARK J.H., Jaung J.Y., Mater. Res. Bull., 47 (2012), 2767.
[5] Yang H.B., LiU M., Lin Y., ZhU J.F., Wang F., Mater. Manuf. Process, 28 (2013), 1024.

[6] Gairola S.P., Verma V., Kumar L., Abdullah Dar M., Annapoorni S., Kotnala P.K., Synthetic Met., 160 (2010), 2315.

[7] Joseph N., Singh S.K., Sirugudu R.K., Murthy V.R.K., Ananthakumar S., Sebastian M.T., Mater. Res. Bull., 48 (2013), 1681.

[8] KIm H.R., KIm B.S., KIm I.S., Mater. Chem. Phys., 135 (2012), 1024.

[9] Panwar V., Kang B., Park J.O., Park S., Mehra R.M., Eur. Polym. J., 45 (2009), 1777.

[10] Nair A.B., Kurian P., Joseph R., Eur. Polym. J., 49 (2013), 247.

[11] Fan Y.Z., Yang H.B., LiU X.Z., Zhu H.Y., Zou G.T., J. Alloy. Compd., 461 (2008), 490.

[12] Wang C., LV R., HuAng Z.H., KAng F.Y., GU J.L., J. Alloy. Compd., 509 (2011), 494.

[13] Xu Z., Huang Y.A., Yang Y., Shen J.Y., Tang T., J. Magn. Magn. Mater, 322 (2010), 3084.

[14] Prusty G., Swain S.K., New Carbon Mater., 27 (2012), 271.

[15] Xiang C., Li L.C., Jin S.Y., Zhang B.Q., Qian H.S., Tong G.X., Mater. Lett., 64 (2011), 1313.

[16] Al-Ghamdi A.A., El-Tantawy F., Compos. Part AAppl. S., 41 (2010), 1693.

[17] LIN W., XI X.R., YU C.S., Synthetic Met., 159 (2009), 619.

[18] Sridhar V., JeOn J.H., OH I.K., Carbon, 48 (2010), 2953.

[19] YAn K., Wu X., An X., XIE X.M., J. Alloy. Compd., 552 (2013), 405.

[20] Deraz N.M., J. Alloy. Compd., 501 (2010), 317.

[21] Bayrakdar H., Yalcln O., Vural S., Esmer K., J. Magn. Magn. Mater., 343 (2013), 86.

[22] Xia A.L., LiU S.K., Jin C.G., Chen L., LV Y.H., Mater. Lett., 105 (2013), 199.

[23] Mounkachi O., Hamedoun M., Belaiche M., Benyoussef A., Masrour R., El Moussaoui H., SAJieddine M., Physica B, 407 (2012), 27.

[24] Li S.M., Zhou H.Y., Zhao L.J., Du L.P., YANG H., Mater. Manuf. Process, 27 (2012), 1285.

[25] Stamenov P., Coey J.M.D., J. Magn. Magn. Mater., $290-291$ (2005), 279.

[26] Kotosonov A.S., Kuvshinnikov S.V., Phys. Lett. A, 229 (1997), 377.

[27] Pradeep A., Priyadharsini P., ChanDRASEKARAN G., J. Magn. Magn. Mater, 320 (2008), 2774.

[28] Cedeno-Mattei Y., Perales-Perez O., Microelectron. J., 40 (2009), 673. 